\title{
Cardiac Stem Cells and their Regenerative Role on Myocardial Infarction
}

\author{
Bin $L^{1}$, Jian $Z^{1}$, Shaheen ${ }^{1}$ and Cheng $L Z^{2^{*}}$
}

${ }^{1}$ College of the First Center Hospital, Tianjin Medical University, Tianjin 300192, China

${ }^{2}$ Department of Cardiology, Tianjin First Center Hospital, Tianjin 300192, China

*Corresponding author: Lu Cheng-zhi, Department of Cardiology, Tianjin First Center Hospital, Tianjin 300192, China, Tel: +86-022-23626585; Fax: +86-022-23626585; E-mail: lucz8@126.com

Rec Date: July 9, 2014, Acc date: October 14, 2014, Pub date: October 16, 2014

Copyright: (C) 2014 Bin L, et al. This is an open-access article distributed under the terms of the Creative Commons Attribution License, which permits unrestricted use, distribution, and reproduction in any medium, provided the original author and source are credited.

\begin{abstract}
Cardiovascular diseases, especially myocardial infarction (MI) are the leading cause of death all over the world. Current treatment strategies of myocardial infarction include drug regimens, percutaneous coronary revascularisation and coronary artery bypass grafting (CABG). Despite the considerable contribution of the interventions mentioned above, the long term benefits remain unsatisfactory. Existing treatments fail to regenerate myocardium that has gone through necrosis or apoptosis. So seeking for new approaches will not only minimize patient suffering but also significantly reduce the cost and resource burdens on a healthcare system that is already stretched to the limit. Recently, transplantation of cardiac stem cells has become a hot topic on regenerative medicine. Mammalian heart has been traditionally regarded as a terminally differentiated organ with no potential for regeneration. However, studies over the past decade have suggested the existence of cardiac stem cells (CSCs) that reside in the heart itself both in normal and pathological states. These cells are self-renewing, clonogenic, and multipotent, i.e, they are capable of differentiating into myocytes, vascular smooth muscle cells, and endothelial cells in appropriate conditions. This review mainly discusses the current research on CSCs, various subpopulations of CSCs and their repair mechanisms in MI.
\end{abstract}

Keywords: Cardiac stem cells; Myocardial infarction; Myocardial regeneration; Stem cell therapy

\section{Abbreviations:}

CSCs: Cardiac Stem Cells; MI: Myocardial Infarction; CABG: Coronary Artery Bypass Grafting; ESCs: Embryonic Stem Cells; BMSCs: Bone Marrow Derived Stem Cells; CDC: Cardiosphere Derived CSCs; SP: Side Population; MCSCs: Myogenic CSCs; VCSCs: Vasculogenic CSCs; IGF-1: Insulin-like Growth Factor-1; HGF: Hepatocyte Growth Factor; SDF-1: Stromal Cell-Derived Factor-1; VEGF: Vascular Endothelial Growth Factor; BFGF: Basic Fibroblast Growth Factor; LVEF: Left Ventricular Ejection Fraction; NF: Nano Fiber

\section{Introduction}

Different stem cell populations have been intensively studied in the last decade as a potential source of new cardiomyocytes to ameliorate the injured myocardium, compensate for the loss of ventricular mass and contractility and eventually restore cardiac functions. An array of cell types has been explored in this respect, including embryonic stem cells (ESCs), skeletal myoblasts, bone marrow derived stem cells (BMSCs), and more recently cardiac stem cells (CSCs) [1]. Although ESCs have an exceptional capacity for proliferation and differentiation, the clinical application of ESCs is limited by their pluripotent nature, teratomas potential and ethical concern. Skeletal myoblasts are not suitable cells, because transplanted myoblasts are unable to turn into cardiomyocytes and they are also associated with life-threatening arrhythmias. However, the BMSCs do not become functional cardiomyocytes in vivo, instead they exert their benefits mainly through indirect paracrine mechanisms $[2,3]$. So it is pressing to find a logical cell source for cell transplantation after MI, which can differentiate into cardiomyocytes directly and effectively. More importantly, overcome ethical, immunological, and safety issues.

In 1994, Soonpaa's group delivered ESCs isolated from transgenic mice directly into the infarcted myocardium of syngeneic hosts, 2 months later, the results suggested that grafted cells could attenuate the development of scar formation and prevent cardiac failure secondary to myocardial infarction [4]. Then mitosis was observed in small amounts of cardiomyocytes both in the peri-infarct zone and normal myocardial tissues, providing that some cardiomyocytes are self-renewal even in pathological condition [5]. The adult heart is composed predominantly of postmitotic cells, but it is not a terminally differentiated organ. It contains replicating myocytes responsible for myocardial regeneration.

The year of 2003, Beltrami first isolated and expanded so-called CSCs capable of committing to the myogenic lineage and reversing cardiac dysfunction in the infarcted heart [6]. The next year, Messina successfully identified and characterized a kind of self-renewal cells from the adult human and murine heart. These cells are clonogenic, express stem and endothelial progenitor cell antigens/markers, and appear to have the properties of adult cardiac stem cells [7]. Other studies reported similar results that CSCs possess the fundamental properties of stem cells and they differentiate into or give rise to all three major cardiac lineages [8-10]. All this compelling evidence has demonstrated the existence of multipotent CSCs in adult heart.

\section{Subpopulations of CSCs}

Multipotent cardiac stem cells are relatively abundant, accessible, and autologous compared to other cell source, which makes them the most attractive and suitable cell type for the treatment of myocardial 
injury. Different subpopulations of CSCs have been identified according to their properties and surface markers. These distinct CSC populations include c-kit+ CSCs, cardiosphere-derived CSCs (CDC), Sca-1+ CSCs, side population (SP) CSCs, Islet-1+ CSCs.

\section{C-kit+ CSCs}

One of the most well-known stem cells is the c-kit+ CSCs. Quantitative data in the animal and human heart have demonstrated that there is one CSC per 30,000-40,000 myocardial cells [11]. CSCs exist in small clusters with a highest density in the atria and the ventricular apex, especially the right atrial appendage [12]. These cells are characterized by expression of c-kit and absence of CD45, additionally, they are blood lineage negative and express transcription factors associated with early cardiac development, such as GATA-4, Nkx2.5, and Mef2C $[6,13,14]$. Moreover, they are the most extensively studied cell source with the ability to form all three cardiac lineages in vitro, which have been applied into clinical trials.

\section{Cardiosphere-derived CSCs}

Another type of CSC that has been exploited in cardiac regeneration therapy is the $\mathrm{CDC}$. The cells yielded from mild enzymatic digestion of the tissue specimens are small, round, phasebright and will form spheroid aggregates in suspension culture, thus are named as Cardiosphere-derived CSCs (CDCs) [7]. CDCs are composed of proliferating c-kit positive cells primarily in their core and differentiating cells expressing cardiac and endothelial cell markers on their periphery $[15,16]$. Abundant evidence suggests that CDCs have the ability of self-renewal, clonogenicity, and differentiation into cardiomyocytes and endothelial cells [7,17]. A head-to-head comparison of CDCs, bone marrow-derived mesenchymal stem cells, adipose tissue-derived mesenchymal stem cells, and bone marrow-derived mononuclear cells showed that CDCs were superior in terms of paracrine factor secretion, angiogenesis, cardiomyogenic differentiation, ischemic tissue preservation, antiremodeling effects, and functional benefit [18]. A Phase I clinical trial has also been performed using CDCs [19].

\section{Sca-1+ CSCs}

Sca-1+ CSCs were identified as another predominant cardiac stem cell population in the adult mouse heart that express stem cell antigen-1 (Sca-1) but not c-kit or blood lineage markers [20]. When treated with oxytocin, Sca-1+ CSCs expressed genes of caridac transcription factors including $\mathrm{Nkx}-2.5$, GATA4 and contractile proteins such as sarcomeric $a$-actin, cardiac troponin I, and MHC, at the same time, a small fraction $(\sim 1 \%)$ of Sca- $1+$ cells exhibited spontaneous beating activity [21]. Furthermore, transplantation of Sca-1+ cells into the acutely infarcted mouse heart resulted in functional promotion by secretion of various cytokines and proteins related to caridac proliferation and regenaration, which show their reparative roles in MI $[22,23]$.

\section{SP CSCs}

Side population (SP) cells are characterized by their expression of the ATP binding cassette transporter ABCG2 and their ability to exclude Hoechst 33342 dye $[24,25]$. Hierlihy et al. was the first to isolate SP cells and found that these cells comprised $\sim 1 \%$ of all cells in the mouse heart [26]. SP CSCs are subdivided into two distinct populations according to their cell phenotype, namely, CD31-/Sca-1+
SP CSCs and CD31+/Sca-1+ SP CSCs. However, only CD31-/Sca-1+ SP CSCs show high cardiomyogenic potential [27]. Still, SP CSCs demonstrate their ability to differentiate into mature cardiomyocytes after 2-3 weeks of co-culture with adult rat ventricular cardiomyocytes [28]. Two years later, SP CSCs from neonatal rat hearts were successfully induced into functional cardiomyocytes through oxytocin or trichostatin A without co-culture with other cell types [29]. Recently, human SP Cells were isolated from biopsies of left atrium $[30,31]$. The properties of these cells will need to be further characterized in the future.

\section{Islet-1+ CSCs}

Islet-1+ CSCs could be isolated from neonatal mouse hearts, and these cells could express the cardiac transcription factors $\mathrm{Nkx} 2.5$ and GATA4, but not Sca-1, CD31, or c-kit [32-34]. Islet-1+ cells are crucial for the formation of the right ventricle, atria, and outflow tract [35]. However, Islet-1+ cells can be found only in neonatal and fetal tissues, yet reduce to low or nonexistent levels in adult hearts, which limits their clinical potential [36].

\section{Mechanisms of CSCs in Cardiac Regeneration}

Until now, the mechanisms involved in cardiac repair caused by CSCs transplantation have been summarized as Cardiomyo Angiogenesis and paracrine mechanisms.

\section{Cardiomyo angiogenesis}

Lots of animal researches and clinical trials have demonstrated that transplanted CSCs could differentiate into new myocytes and vessels. Current researches inform that IP3R-mediated Ca2+ oscillations control CSCs growth and their regenerative potential. In the unfavorable environment of the necrotic tissue post-myocardial infarction, the highly expressed ATP increases the frequency of $\mathrm{Ca} 2+$ oscillations among neighboring CSCs, which initiates and enhances the engraftment, proliferation, and regeneration of a myocyte progeny $[13,37]$. Additionally, the latest research revealed that the heart contains two distinct subpopulations of CSCs: myogenic CSCs (mCSCs), characterized by expression of c-kit, which are mainly responsible for regenerating cardiomyocytes [38], and vasculogenic CSCs (vCSCs), which express c-kit as well as KDR, are more committed to the turnover of coronary vessels [39]. Both of these two subpopulations possess the fundamental properties of stem cells: selfrenewing, clonogenic, and multipotent [40]. All this evidence described above provides convincing proof that the improvement of cardiac function by CSCs therapy is mediated partially by cardiomyo angiogenesis mechanism if not all.

\section{Paracrine and exosomes}

Although transplantation of CSCs has showed its beneficial effects in mediating cardiac protection, it is believed that the positive outcomes of stem cell transplantation are regulated mainly through production and secretion of growth factors and cytokines by the engrafted stem cells [41]. The paracrine factors secreted by the large number of injected stem cells could contribute to rearrange the postischemic microenvironment and promote angiogenesis, inhibit apoptosis, and stimulate myocyte proliferation [42-44]. CSCs possess growth factor receptor systems such as IGF-1/IGF-1R, HGF/c-Met, and SDF-1/CXCR4, when integrated with growth factors, the downstream signalling pathways will be activated to induce cell 
migration, proliferation and differentiation $[45,46]$. Several growth factors and cytokines have been identified, and these include VEGF, HGF, IGF-1, SDF-1, etc. They play their role in cardiac functional improvement through corresponding receptors and signalling pathways. For example, delivery of IGF-1 exerts a prosurvival effect on CSCs through induction of the IGF-1 receptor and PI3K/Akt/ GSK-3beta signalling [47]. While VEGF shows it's prosurvival and anti-apoptosis potential via activating SDF-1/CXCR4 axis and downstream STAT3 and ERK1/2 pathway [48-50]. Overall, paracrine effectors are crucial regulators involved in CSCs homing, expansion and differentiation.

Exosomes are membrane vesicles with a diameter of $40-100 \mathrm{~nm}$, which are emerging as an attractive vector of paracrine signals delivered by CSCs. Exosomes are stored intracellularly in endosomal compartments and are secreted when these multivesicular structures fuse with the cell plasma membrane [51-54]. Exosomes carry a specific set of proteins derived from the plasma membrane, endocytic pathway, and the cytosol, which play important roles in cell penetration, invasion and fusion events, and regulate exosome docking and membrane fusion [55,56]. Exosomes also contain annexins, metabolic enzymes, ribosomal proteins, signal transduction molecules, adhesion molecules, ATPases, cytoskeletal and ubiquitin molecules, growth factors, cytokines and miRNA molecules [57], among which, miRNAs, an important regulators in CSC-mediated cardiac repair after MI are best studied. A research have recently reported that miRNA families plays important roles in the transition of cellular proliferation in CSCs in vivo,and may be an crucial modulator in the process of bone morphogenetic protein (BMP)-2-regulated myocardial differentiation due to their repression of cardiac progenitor genes IsI1 and Tbx1 [58-60]. In addition, miRNA could repress CMC progenitor cell death via targeting receptor interacting protein 1 [61]. Altogether, exosomes act as vectors for the intercellular exchange of biological signals and information, which mediate cell activation, phenotypic changes, and reprogrmming of cell function. Exosomes may be a key mechanism by which cardiac progenitors communicate with each other and deliver paracrine signals to neighboring cells [62-65].

\section{Experimental and Preclinical Research on CSCs}

In the last years tremendous effort has been undertaken to evaluate CSCs for their safety, feasibility, and efficacy on cardiac repair and regeneration, including small animal experimental studies and preclinical large animal trials.

\section{Experimental research}

Small animal models of MI have been widely used to study the effects of transplanted CSCs and they did document the structural and functional benefits.

Transplanting CSCs into a rat model with a 90-min coronary occlusion following by 4 hours of reperfusion, Dawn et al. found that CSCs were able to induce regeneration, and decrease myocardial infarct size by $29 \%$ [66]. Another study by Wang et al. revealed that delivery of Sca-1+/CD31- cells into the acutely infarcted mouse heart attenuated functional decline and adverse structural remodeling as evidenced by an increased left ventricular ejection fraction, a decreased end-diastolic and systolic dimension, a significant increase of myocardial neovascularization, and modest cardiomyocyte regeneration [67]. Smith et al. transplanted human CDCs into the border zone of myocardial infarcts in immunodeficient mice. 20 days later, the percentage of viable myocardium within the infarct zone was greater in the CDC-treated group $(24.9 \pm 1.1 \%)$ than in the control group(17.7 $\pm 1.8 \%, P 0.01)$; likewise, left ventricular ejection fraction was significantly higher in the CDC-treated group $(42.8 \pm 3.3 \%$ vs 25.0 $\pm 2.0 \%$ for control group) [68]. Abundant studies finished in recent years further confirmed that administrated CSCs in the setting of MI produced beneficial structural and functional effects in small animal models [69-72].

\section{Preclinical research}

Similar results have already been obtained in large animal models. The pig, which is more similar in tissue biology, size, and physiology to the human than the rodent models commonly used has proven a very productive and frequently used preclinical large animal model for regenerative therapy. Johnston et al. administered CDCs to both healthy and infarcted pigs at 4 weeks after MI through intracoronary infusion. 8 weeks later, CDCs treatment formed new cardiac tissue, reduced relative infarct size, attenuated adverse remodeling, and improved hemodynamics [73]. A randomized, blinded, and placebocontrolled study showed that Intramyocardial injection of autologous CDCs effectively halted the deterioration in LVEF and efficiently improved echocardiographic and hemodynamic indexes after large scale of anteroseptal myocardial infarction [74]. In a study by Bolli R et al., autologous CSCs $(n=11)$ or vehicle $(n=10)$ were infused into the infarct-related artery of pigs 3 months after MI. One month later, CSCs-treated pigs exhibited significantly greater LVEF $(51.7 \pm 2.0 \%$ versus $42.9 \pm 2.3 \%, \mathrm{P}<0.01$ ), systolic thickening fraction in the infarcted LV wall, and maximum LV dP/dt, as well as lower LV enddiastolic pressure. The expression of cardiac markers as troponin I, troponin T, myosin heavy chain, connexin- 43 , and $\alpha$-sarcomeric actin was a strong reflection of myocardial regeneration. Some engrafted CSCs also formed vascular structures and expressed $\alpha$-smooth muscle actin [75].

In summary, all these animal studies have shown that transplantation of autologous CSCs improves regional and global left ventricular function and promotes cardiac and vascular regeneration, thus laid a solid foundation for clinical trials.

\section{Clinical trials}

Cell-based therapies to regenerate the damaged myocardium using CSCs have been performed in the recently completed SCIPIO and CADUCEUS clinical trials.

In the open label, randomised phase 1 SCIPIO trial, sixteen patients with post infarction left ventricular dysfunction (ejection fraction $\leq 40 \%$ ) who had undergone coronary artery bypass grafting, received 500,000-1 million of autologous c-kit+ CSCs intracoronary, nearly 4 months after surgery. In the control group no treatment was given. The primary endpoint was short-term safety of CSCs and the secondary endpoint was efficacy. LVEF increased progressively from a mean of $30.3 \%$ before CSC infusion to $38.5 \% 4$ months after transplantation, whereas the LVEF did not change in the control patients, during the corresponding time interval. Moreover, in the eight patients who completed the 1 year of follow-up, LVEF increased by $12 \mathrm{EF}$ points vs. baseline. Cardiac MRI of seven of the treated patients showed that infarct size decreased by $24 \%$ at 4 months and $30 \%$ at 1 year [76].

In the prospective, randomized CADUCEUS trial, patients with left ventricular ejection fraction of $25-45 \%$ were consecutively enrolled in 
the treatment and control groups. Autologous CDCs up to 25 million were infused into the infarct-related artery of the 17 patients assigned as treatment group, 1.5-3 months after myocardial infarction. 8 patients received standard care and acted as the control group. Compared with controls at 6 months, MRI analysis of patients treated with CDCs showed significant reductions in scar size and mass, increases viable heart mass, regional contractility, and regional systolic wall thickening. However, changes in end-diastolic volume, endsystolic volume, and LVEF did not differ between groups at 6 months [19].

Additionally, two promising clinical trials utilize CSCs for treatment of ischemic heart diseases are still in progress, the results have yet to be reported.

In the ALCADIA trial (NCT00981006), 6 patients of ischemic heart failure after $C A B G$ surgery received implantation of autologous CDCs together with a biodegradable gelatin-hydrogel infused with basic fibroblast growth factor (bFGF). Preliminary data at 6 months reported an improvement in LVEF (from $26.7 \%$ to $35.8 \%$ by $3-\mathrm{D}$ echo and $22.6 \%$ to $34.7 \%$ by MRI), a decrease in infarct size by MRI (from $23 \%$ to $19.7 \%$ ), as well as a decrease in wall motion score (from 17.2 to 6.6) [77].

The phase I/II "Allogeneic heart stem cells to achieve myocardial regeneration" (ALLSTAR) trial (NCT01458405), led by Eduardo Marban, is ongoing to test the safety of allogeneic CDCs. It is the first time to investigate the allogeneic use of CSCs in humans, and the results are awaited [78].

\section{New Strategies to Promote CSCs Survival, and Proliferation}

Growing evidence has suggested that CSCs exert great effects on cardiac repair post-MI. But only a small percentage of donor cells could successfully be engrafted into the damaged myocardium due to the harsh microenvironments after infarction. The unfavourable microenvironment of the necrotic myocardium together with diffuse inflammatory infiltrates interferes with homing, survival, and growth of the administered cells, which are critical variables of successful myocardial repair. Therefore, it is imperative to look for some new strategies to enhance the survival rate and long-term engraftment of CSCs after transplantation.

\section{Delivery of biologic factors}

Great efforts have been made to create more conducive myocardial environment for CSCs proliferation. Different cytokines or growth factors are used to boost cell survival, persistence, and proliferation. In the damaged dog and pig heart, CSCs transplantation as well as in situ activation by co-administered IGF-1and HGF has been shown to be a practical and effective strategy to prolong cell survival, induce cardiovascular regeneration, and improve left ventricular function. Such myocardial reconstitution caused by combination delivery of IGF-1 and HGF can promote a significant restoration of dead tissue, resulting in a marked recovery of contractile performance of the infarcted heart $[79,80]$.

\section{Gene transfection}

Based on the observations that HGF gene transferred into human bone marrow- and adipose tissue-derived stem cells highlights great regenerative effects [81-84], a novel powerful therapeutic strategy, gene therapy, has been applied to enhance the ability of CSCs to promote myocardial regeneration. Overexpression of SDF-1 in the infarcted mice heart by rAAV1-SDF-1a-eGFP infection resulted in more CSCs retention to the infarcted myocardium, a higher percentage of proliferation, and reduced infarcted area via CXCR4/ PI3K pathway [85]. Targeted delivery of human VEGF gene via complexes of magnetic nanoparticle-adenoviral vectors exhibited higher capillary and arteriole density and lower collagen deposition and significantly improved left ventricular function [86].

\section{Precondition with low oxygen and growth factors}

CSCs preconditioned by exposure to low oxygen ex vivo are more resistant to ischemic microenvironment. A study in 2009 provided evidence that CSCs subjected to ischemic preconditioning markedly augmented c-kit+ cells recruitment to the ischemic myocardium and enhanced protection against ischemic cardiac injury after myocardial infarction. Four weeks after treatment, infarct size and heart function were significantly better in mice administered hypoxia-preconditioned CSCs than in mice treated with cells cultured under normoxic conditions. Furthermore, these effects were largely abolished by the addition of a CXCR4 inhibitor, indicating that the benefits of hypoxic preconditioning are mediated by the SDF-1/CXCR4 axis [87]. Subsequent experiments have also reported similar results that implantation of low $\mathrm{O} 2$ pre-cultured CSCs into infarcted hearts of mice led to greater cell engraftment and better functional recovery compared with that in normoxic stem cells [88-90]. A newly published article indicates that hypoxic preconditioningeffect [91].

An alternative method to promote survival is to precondition CSCs with growth factors prior to delivery into the recipient heart. Preconditioning Sca-1+ CSCs with IGF-1 before transplantatation enhanced cell survival via PI3K/Akt-dependent caspase-3 downregulation and reprogramed cardiomyogenic differentiation [92]. CSCs activated by IGF-1and HGF, ex vivo, formed conductive and intermediate-sized coronary arteries together with resistance arterioles and capillaries [38].

\section{Engineered cell delivery}

With the rapid progress in the study of biological materials, tissue engineering has gradually become an alternative strategy on cardiac cell therapy. The injectable biomaterials such as hydrogels, gelatines, nanofibers, and self-assembling peptides have been used as vehicles for cell delivery. These biomaterials can provide a scaffold that mimics natural extracellular matrix under physiological conditions, reducing cell washout from the injection site and preventing apoptosis triggering attributable to anoikis. They also possess a reservoir for controlled release of growth factors. In addition, embedded in bioengineered tissues and supported by extracellular matrix, transplanted cells would have a better chance to survive and engraft in the cardiac microenvironment in comparison to direct exposure to injured tissue via injection [93]. In the rat MI model, nanofibers were used to deliver IGF-1 along with CPCs. Compared with infarcts exposed to CPCs or NF-IGF-1 alone, combination therapy resulted in a greater increase in the ratio of left ventricular mass to chamber volume and a better preservation of $+\mathrm{dP} / \mathrm{dt},-\mathrm{dP} / \mathrm{dt}$, and ejection fraction. The number of newly formed myocytes with combination therapy was 32\% and 230\% higher than with CPCs and NF-IGF-1, respectively. Similarly, the length density of newly formed coronary arterioles with both CPCs and NF-IGF- 1 was $3 \%$ and $83 \%$ greater than with CPCs and NF-IGF-1 alone, respectively [94]. Similar progress has been made that 
biomaterials carrying cytokines such as bFGF, IGF-1, and VEGF modulate the post-ischemic microenvironment to enhance CSCs engraftment and differentiation. This novel strategy demonstrates significant functional improvements after myocardial infarction and may potentially represent a therapeutic approach to be studied in a clinical trial [95-100].

\section{Summary and Conclusions}

The findings that the adult heart harbors a regenerative multipotent cell population conclusively dispel the notion of the heart as a terminally differentiated organ without self-renewal potential, representing a paradigm shift in cardiovascular biology. Although initial encouraging results have been achieved from preclinical and clinical studies that administration of CSCs can induce cardiogenesis and neovasculogenesis, additionally, improve recovery of the damaged heart function, there still remain many challenging problems to be solved. Currently, the conditions of isolation, augmentation, and purification of CSCs differ among different laboratories. Time consuming, and the reliability of autologous CSC culture and expansion make the clinical application of CSC transplantation much difficult, especially in their application in the acute post-MI phase. So it is necessary to establish a standard protocol for isolation and culture of CSCs in vitro, which is simple, effective, and reproducible. Available routes of CSC delivery include intravenous, intracoronary, epicardial, endocardial, and coronary sinus injection, each of which has its own advantages and disadvantages, respectively. Despite major advances made in delivering cells to the ischemic heart, low engraftment and survival rate still remains as one of the major hurdles of current cell delivery methods. Subsequent years have seen the prosperity of new ways to deal with the problems of cell survival, persistence, and proliferation, including cell preconditioning or genetic modification prior to CSC delivery or codelivery of CSCs directly into the myocardium with growth factors or degradable biomaterials such as nanofibers and hydrogels. Furthermore, the mechanisms underlying the differentiation of CSCs have not been well understood yet, making it difficult to impose precise regulation on their directed differentiation. Other controversies remaining in cell dose, optimal time for injection and whether the application of gene therapy will lead to cancerization wait to be handled. Though faced with many challenges, CSC therapy, acting as an exciting and dynamic area of research, has shown its great potential to improve recovery of myocardial infarction. With further study of regulation systems and signal transduction mechanisms and development of more large-scale, randomized and double-blind controlled trials, CSC transplantation will bring significant and long-term impact on socioeconomics and patient well-being.

\section{References}

1. Roccio M, Goumans MJ, Sluijter JP, Doevendans PA (2008) Stem cell sources for cardiac regeneration. Panminerva Med 50: 19-30.

2. Rose RA, Jiang H, Wang X, Helke S, Tsoporis JN, et al. (2008) Bone marrow-derived mesenchymal stromal cells express cardiacspecific markers, retain the stromal phenotype, and do not become functional cardiomyocytes in vitro. Stem Cells 26: 2884-2892.

3. Martin-Rendon E, Brunskill SJ, Hyde CJ, Stanworth SJ, Mathur A, et al. (2008) Autologous bone marrow stem cells to treat acute myocardial infarction: a systematic review. Eur Heart J 29: 1807-1818.

4. Soonpaa MH, Koh GY, Klug MG, Field LJ (1994) Formation of nascent intercalated disks between grafted fetal cardiomyocytes and host myocardium. Science 264: 98-101
5. Anversa P, Nadal-Ginard B (2002) Myocyte renewal and ventricular remodelling. Nature 415: 240-243.

6. Beltrami AP, Barlucchi L, Torella D, Baker M, Limana F, et al. (2003) Adult cardiac stem cells are multipotent and support myocardial regeneration. Cell 114: 763-776.

7. Messina E, De Angelis L, Frati G, Morrone S, Chimenti S, et al. (2004) Isolation and expansion of adult cardiac stem cells from human and murine heart. Circ Res 95: 911-921.

8. Bearzi C, Rota M, Hosoda T, Tillmanns J, Nascimbene A, et al. (2007) Human cardiac stem cells. Proc Natl Acad Sci U S A 104: 14068-14073.

9. Bergmann O, Bhardwaj RD, Bernard S, Zdunek S, Barnabé-Heider F, et al. (2009) Evidence for cardiomyocyte renewal in humans. Science 324: 98-102.

10. Hsieh PC, Segers VF, Davis ME, MacGillivray C, Gannon J, et al. (2007) Evidence from a genetic fate-mapping study that stem cells refresh adult mammalian cardiomyocytes after injury. Nat Med 13: 970-974.

11. Wen Z, Mai Z, Zhang H, Chen Y, Geng D, et al. (2012) Local activation of cardiac stem cells for post-myocardial infarction cardiac repair. J Cell Mol Med 16: 2549-2563.

12. Reinecke H, Minami E, Zhu WZ, Laflamme MA (2008) Cardiogenic differentiation and transdifferentiation of progenitor cells. Circ Res 103: 1058-1071.

13. Ferreira-Martins J, Ogórek B, Cappetta D, Matsuda A, Signore S, et al. (2012) Cardiomyogenesis in the developing heart is regulated by c-kitpositive cardiac stem cells. Circ Res 110: 701-715.

14. He JQ, Vu DM, Hunt G, Chugh A, Bhatnagar A, et al. (2011) Human cardiac stem cells isolated from atrial appendages stably express c-kit. PLoS One 6: e27719.

15. Barile L, Chimenti I, Gaetani R, Forte E, Miraldi F, et al. (2007) Cardiac stem cells: isolation, expansion and experimental use for myocardial regeneration. Nat Clin Pract Cardiovasc Med 4 Suppl 1: S9-9S14.

16. Barile L, Messina E, Giacomello A, Marbán E (2007) Endogenous cardiac stem cells. Prog Cardiovasc Dis 50: 31-48.

17. Davis DR, Zhang Y, Smith RR, Cheng K, Terrovitis J, et al. (2009) Validation of the cardiosphere method to culture cardiac progenitor cells from myocardial tissue. PLoS One 4: e7195.

18. Li TS, Cheng K, Malliaras K, Smith RR, Zhang Y, et al. (2012) Direct comparison of different stem cell types and subpopulations reveals superior paracrine potency and myocardial repair efficacy with cardiosphere-derived cells. J Am Coll Cardiol 59: 942-953.

19. Makkar RR, Smith RR, Cheng K, Malliaras K, Thomson LE, et al. (2012) Intracoronary cardiosphere-derived cells for heart regeneration after myocardial infarction (CADUCEUS): a prospective, randomised phase 1 trial. Lancet 379: 895-904.

20. Oh H, Bradfute SB, Gallardo TD, Nakamura T, Gaussin V, et al. (2003) Cardiac progenitor cells from adult myocardium: homing, differentiation, and fusion after infarction. Proc Natl Acad Sci U S A 100: 12313-12318.

21. Matsuura K, Nagai T, Nishigaki N, Oyama T, Nishi J, et al. (2004) Adult cardiac Sca-1-positive cells differentiate into beating cardiomyocytes. J Biol Chem 279: 11384-11391.

22. Matsuura K, Honda A, Nagai T, Fukushima N, Iwanaga K, et al. (2009) Transplantation of cardiac progenitor cells ameliorates cardiac dysfunction after myocardial infarction in mice. J Clin Invest 119: 2204-2217.

23. Samal R, Ameling S, Wenzel K, Dhople V, Völker U, et al. (2012) OMICS-based exploration of the molecular phenotype of resident cardiac progenitor cells from adult murine heart. J Proteomics 75: 5304-5315.

24. Pfister O, Oikonomopoulos A, Sereti KI, Sohn RL, Cullen D, et al. (2008) Role of the ATP-binding cassette transporter Abcg2 in the phenotype and function of cardiac side population cells. Circ Res 103: 825-835.

25. Martin CM, Meeson AP, Robertson SM, Hawke TJ, Richardson JA, et al. (2004) Persistent expression of the ATP-binding cassette transporter, Abcg2, identifies cardiac SP cells in the developing and adult heart. Dev Biol 265: 262-275. 
26. Hierlihy AM, Seale P, Lobe CG, Rudnicki MA, Megeney LA (2002) The post-natal heart contains a myocardial stem cell population. FEBS Lett 530: 239-243.

27. Leri A, Kajstura J, Anversa P (2011) Role of cardiac stem cells in cardiac pathophysiology: a paradigm shift in human myocardial biology. Circ Res 109: 941-961.

28. Pfister O, Mouquet F, Jain M, Summer R, Helmes M, et al. (2005) CD31but Not CD31+ cardiac side population cells exhibit functional cardiomyogenic differentiation. Circ Res 97: 52-61.

29. Oyama T, Nagai T, Wada H, Naito AT, Matsuura K, et al. (2007) Cardiac side population cells have a potential to migrate and differentiate into cardiomyocytes in vitro and in vivo. J Cell Biol 176: 329-341.

30. Alfakir M, Dawe N, Eyre R, Tyson-Capper A, Britton K, et al. (2012) The temporal and spatial expression patterns of ABCG2 in the developing human heart. Int J Cardiol 156: 133-138.

31. Sandstedt J, Jonsson M, Kajic K, Sandstedt M, Lindahl A, et al. (2012) Left atrium of the human adult heart contains a population of side population cells. Basic Res Cardiol 107: 255.

32. Laugwitz KL, Moretti A, Lam J, Gruber P, Chen Y, et al. (2005) Postnatal isl1+ cardioblasts enter fully differentiated cardiomyocyte lineages. Nature 433: 647-653.

33. Moretti A, Lam J, Evans SM, Laugwitz KL (2007) Biology of Isl1+ cardiac progenitor cells in development and disease. Cell Mol Life Sci 64: 674-682.

34. Bu L, Jiang X, Martin-Puig S, Caron L, Zhu S, et al. (2009) Human ISL1 heart progenitors generate diverse multipotent cardiovascular cell lineages. Nature 460: 113-117.

35. Moretti A, Caron L, Nakano A, Lam JT, Bernshausen A, et al. (2006) Multipotent embryonic isl1+ progenitor cells lead to cardiac, smooth muscle, and endothelial cell diversification. Cell 127: 1151-1165.

36. Simpson DL, Mishra R, Sharma S, Goh SK, Deshmukh S, et al. (2012) A strong regenerative ability of cardiac stem cells derived from neonatal hearts. Circulation 126: S46-53.

37. Ferreira-Martins J, Rondon-Clavo C, Tugal D, Korn JA, Rizzi R, et al. (2009) Spontaneous calcium oscillations regulate human cardiac progenitor cell growth. Circ Res 105: 764-774.

38. Tillmanns J, Rota M, Hosoda T, Misao Y, Esposito G, et al. (2008) Formation of large coronary arteries by cardiac progenitor cells. Proc Natl Acad Sci U S A 105: 1668-1673.

39. Bearzi C, Leri A, Lo Monaco F, Rota M, Gonzalez A, et al. (2009) Identification of a coronary vascular progenitor cell in the human heart. Proc Natl Acad Sci U S A 106: 15885-15890.

40. Hosoda T (2012) C-kit-positive cardiac stem cells and myocardial regeneration. Am J Cardiovasc Dis 2: 58-67.

41. Chimenti I, Smith RR, Li TS, Gerstenblith G, Messina E, et al. (2010) Relative roles of direct regeneration versus paracrine effects of human cardiosphere-derived cells transplanted into infarcted mice. Circ Res 106: 971-980.

42. Nadal-Ginard B, Anversa P, Kajstura J, Leri A (2005) Cardiac stem cells and myocardial regeneration. Novartis Found Symp 265: 142-154.

43. Tang J, Wang J, Kong X, Yang J, Guo L, et al. (2009) Vascular endothelial growth factor promotes cardiac stem cell migration via the PI3K/Akt pathway. Exp Cell Res 315: 3521-3531.

44. Fatma S, Selby DE, Singla RD, Singla DK (2010) Factors Released from Embryonic Stem Cells Stimulate c-kit-FLK-1(+ve) Progenitor Cells and Enhance Neovascularization. Antioxid Redox Signal 13: 1857-1865.

45. Urbanek K, Rota M, Cascapera S, Bearzi C, Nascimbene A, et al. (2005) Cardiac stem cells possess growth factorreceptor systems that after activation regenerate the infarcted myocardium, improving ventricular function and longterm survival. Circ Res 97: 663-673.

46. Padin-Iruegas ME, Misao Y, Davis ME, Segers VF, Esposito G, et al. (2009) Cardiac progenitor cells and biotinylated insulin-like growth factor-1 nanofibers improve endogenous and exogenous myocardial regeneration after infarction. Circulation 120: 876-887.
47. Rota M, Padin-Iruegas ME, Misao Y, De Angelis A, Maestroni S, et al. (2008) Local activation or implantation of cardiac progenitor cells rescues scarred infarcted myocardium improving cardiac function. Circ Res 103: 107-116.

48. Hu X, Dai S, Wu WJ, Tan W, Zhu X, et al. (2007) Stromal cell derived factor-1 alpha confers protection against myocardial ischemia/ reperfusion injury: role of the cardiac stromal cell derived factor-1 alpha CXCR4 axis. Circulation 116: 654-663.

49. Huang C, Gu H, Yu Q, Manukyan MC, Poynter JA, et al. (2011) Sca-1+ cardiac stem cells mediate acute cardioprotection via paracrine factor SDF-1 following myocardial ischemia/reperfusion. PLoS One 6: e29246.

50. Segers VF, Tokunou T, Higgins LJ, MacGillivray C, Gannon J, et al. (2007) Local delivery of protease-resistant stromal cell derived factor-1 for stem cell recruitment after myocardial infarction. Circulation 116: 1683-1692.

51. Théry C, Amigorena S, Raposo G, Clayton A (2006) Isolation and characterization of exosomes from cell culture supernatants and biological fluids. Curr Protoc Cell Biol Chapter 3: Unit 3.

52. Mathivanan S, Ji H, Simpson RJ (2010) Exosomes: extracellular organelles important in intercellular communication. J Proteomics 73: 1907-1920.

53. Quesenberry PJ, Aliotta JM (2010) Cellular phenotype switching and microvesicles. Adv Drug Deliv Rev 62: 1141-1148.

54. Sahoo S, Losordo DW (2014) Exosomes and cardiac repair after myocardial infarction. Circ Res 114: 333-344.

55. Mathivanan S, Simpson RJ (2009) ExoCarta: A compendium of exosomal proteins and RNA. Proteomics 9: 4997-5000.

56. Ostrowski M, Carmo NB, Krumeich S, Fanget I, Raposo G, et al. (2010) Rab27a and Rab27b control different steps of the exosome secretion pathway. Nat Cell Biol 12: 19-30.

57. Valadi H, Ekström K, Bossios A, Sjöstrand M, Lee JJ, et al. (2007) Exosome-mediated transfer of mRNAs and microRNAs is a novel mechanism of genetic exchange between cells. Nat Cell Biol 9: 654-659.

58. Ong SG, Lee WH, Huang M, Dey D1, Kodo K, et al. (2014) Cross Talk of Combined Gene and Cell Therapy in Ischemic Heart Disease: Role of Exosomal MicroRNA Transfer. Circulation 130: S60-69.

59. Wang J, Greene SB, Bonilla-Claudio M, Tao Y, Zhang J, et al. (2010) Bmp signaling regulates myocardial differentiation from cardiac progenitors through a MicroRNA-mediated mechanism. Dev Cell 19: 903-912.

60. Sirish P, López JE, Li N, Wong A, Timofeyev V, et al. (2012) MicroRNA profiling predicts a variance in the proliferative potential of cardiac progenitor cells derived from neonatal and adult murine hearts. J Mol Cell Cardiol 52: 264-272.

61. Liu J, van Mil A, Vrijsen K, Zhao J, Gao L, et al. (2011) MicroRNA-155 prevents necrotic cell death in human cardiomyocyte progenitor cells via targeting RIP1. J Cell Mol Med 15: 1474-1482.

62. Akyurekli C, Le Y, Richardson RB, Fergusson D, Tay J, et al. (2014) A Systematic Review of Preclinical Studies on the Therapeutic Potential of Mesenchymal Stromal Cell-Derived Microvesicles. Stem Cell Rev .

63. 64. Barile L, Lionetti V, Cervio E, Matteucci M, Gherghiceanu M, et al. (2014) Extracellular vesicles from human cardiac progenitor cells inhibit cardiomyocyte apoptosis and improve cardiac function after myocardial infarction. Cardiovasc Res 103: 530-541.

64. Bian S, Zhang L, Duan L, Wang X, Min Y, et al. (2014) Extracellular vesicles derived from human bone marrow mesenchymal stem cells promote angiogenesis in a rat myocardial infarction model. J Mol Med (Berl) 92: 387-397.

65. Ibrahim AG, Cheng K, Marbán E (2014) Exosomes as critical agents of cardiac regeneration triggered by cell therapy. Stem Cell Reports 2: 606-619.

66. Dawn B, Stein AB, Urbanek K, Rota M, Whang B, et al. (2005) Cardiac stem cells delivered intravascularly traverse the vessel barrier, regenerate infarcted myocardium, and improve cardiac function. Proc Natl Acad Sci U S A 102: 3766-3771. 
67. Wang X, Hu Q, Nakamura Y, Lee J, Zhang G, et al. (2006) The role of the sca-1+/CD31- cardiac progenitor cell population in postinfarction left ventricular remodeling. Stem Cells 24: 1779-1788.

68. Smith RR, Barile L, Cho HC, Leppo MK, Hare JM, et al. (2007) Regenerative potential of cardiosphere-derived cells expanded from percutaneous endomyocardial biopsy specimens. Circulation 115 896-908.

69. Li Q, Guo Y, Ou Q, Chen N, Wu WJ, et al. (2011) Intracoronary administration of cardiac stem cells in mice: a new, improved technique for cell therapy in murine models. Basic Res Cardiol 106: 849-864.

70. Tang XL, Rokosh G, Sanganalmath SK, Yuan F, Sato H, et al. (2010) Intracoronary administration of cardiac progenitor cells alleviates left ventricular dysfunction in rats with a 30-day-old infarction. Circulation 121: 293-305

71. Ye J, Boyle A, Shih H, Sievers RE, Zhang Y, et al. (2012) Sca-1+ cardiosphere-derived cells are enriched for Isl1-expressing cardiac precursors and improve cardiac function after myocardial injury. PLoS One 7: e30329.

72. Li TS, Cheng K, Lee ST, Matsushita S, Davis D, et al. (2010) Cardiospheres recapitulate a niche-like microenvironment rich in stemness and cell-matrix interactions, rationalizing their enhanced functional potency for myocardial repair. Stem Cells 28: 2088-2098.

73. Johnston PV, Sasano T, Mills K, Evers R, Lee ST, et al. (2009) Engraftment, differentiation, and functional benefits of autologous cardiosphere-derived cells in porcine ischemic cardiomyopathy. Circulation 120: 1075-1083. 7-1083.

74. Lee ST, White AJ, Matsushita S, Malliaras K, Steenbergen C, et al. (2011) Intramyocardial injection of autologous cardiospheres or cardiospherederived cells preserves function and minimizes adverse ventricular remodeling in pigs with heart failure post-myocardial infarction. J Am Coll Cardiol 57: 455-465.

75. Bolli R, Tang XL, Sanganalmath SK, Rimoldi O, Mosna F, et al. (2013) Intracoronary delivery of autologous cardiac stem cells improves cardiac function in a porcine model of chronic ischemic cardiomyopathy. Circulation 128: 122-131.

76. Bolli R, Chugh AR, D'Amario D, Loughran JH, Stoddard MF, et al. (2011) Cardiac stem cells in patients with ischaemic cardiomyopathy (SCIPIO): initial results of a randomised phase 1 trial. Lancet 378: 1847-1857.

77. Takehara N. The ALCADIA (Autologous Human Cardiac-Derived Stem Cell to Treat Ischemic Cardiomyopathy) trial. Paper presented at the American Heart Association Scientific Sessions; November 4-6, 2012; Los Angeles, CA, USA.

78. Capricor. Allogeneic Heart Stem Cells to Achieve Myocardial Ren ᄀeration (ALLSTAR). 2012. In: ClinicalTrials.gov. Available from: http://clinicaltrials.gov/show/NCT01458405. Accessed November 14, 2012.

79. Ellison GM, Torella D, Dellegrottaglie S, Perez-Martinez C, Perez de Prado A, et al. (2011) Endogenous cardiac stem cell activation by insulinlike growth factor-1/hepatocyte growth factor intracoronary injection fosters survival and regeneration of the infarcted pig heart. J Am Coll Cardiol 58: 977-986.

80. Linke A, Müller P, Nurzynska D, Casarsa C, Torella D, et al. (2005) Stem cells in the dog heart are self-renewing, clonogenic, and multipotent and regenerate infarcted myocardium, improving cardiac function. Proc Natl Acad Sci U S A 102: 8966-8971.

81. Guo Y, He J, Wu J, Yang L, Dai S, et al. (2008) Locally overexpressing hepatocyte growth factor prevents post-ischemic heart failure by inhibition of apoptosis via calcineurin-mediated pathway and angiogenesis. Arch Med Res 39: 179-188.

82. Shabbir A, Zisa D, Suzuki G, Lee T (2009) Heart failure therapy mediated by the trophic activities of bone marrow mesenchymal stem cells: a noninvasive therapeutic regimen. Am J Physiol Heart Circ Physiol 296: H1888-1897.
83. Zhang G, Hu Q, Braunlin EA, Suggs LJ, Zhang J (2008) Enhancing efficacy of stem cell transplantation to the heart with a PEGylated fibrin biomatrix. Tissue Eng Part A 14: 1025-1036.

84. Zhu XY, Zhang XZ, Xu L, Zhong XY, Ding Q, et al. (2009) Transplantation of adipose-derived stem cells overexpressing hHGF into cardiac tissue. Biochem Biophys Res Commun 379: 1084-1090.

85. Wang K, Zhao X, Kuang C, Qian D, Wang H, et al. (2012) Overexpression of SDF-1 $1 \pm$ enhanced migration and engraftment of cardiac stem cells and reduced infarcted size via CXCR4/PI3K pathway. PLoS One 7: e43922.

86. Zhang Y, Li W, Ou L, Wang W, Delyagina E, et al. (2012) Targeted delivery of human VEGF gene via complexes of magnetic nanoparticleadenoviral vectors enhanced cardiac regeneration. PLoS One 7: e39490.

87. Tang YL, Zhu W, Cheng M, Chen L, Zhang J, et al. (2009) Hypoxic preconditioning enhances the benefit of cardiac progenitor cell therapy for treatment of myocardial infarction by inducing CXCR4 expression. Circ Res 104: 1209-1216.

88. Yan F, Yao Y, Chen L, Li Y, Sheng Z, et al. (2012) Hypoxic preconditioning improves survival of cardiac progenitor cells: role of stromal cell derived factor-11̂It-CXCR4 axis. PLoS One 7: e37948.

89. Li TS, Cheng K, Malliaras K, Matsushita N, Sun B, et al. (2011) Expansion of human cardiac stem cells in physiological oxygen improves cell production efficiency and potency for myocardial repair. Cardiovasc Res 89: 157-165.

90. Sanada F, Kim J, Czarna A, Chan NY, Signore S, et al. (2014) c-Kitpositive cardiac stem cells nested in hypoxic niches are activated by stem cell factor reversing the aging myopathy. Circ Res 114: 41-55.

91. Hu S, Yan G, Xu H, He W, Liu Z, et al. (2014) Hypoxic preconditioning increases survival of cardiac progenitor cells via the pim-1 kinasemediated anti-apoptotic effect. Circ J 78: 724-731.

92. Lu G, Haider HK, Jiang S, Ashraf M (2009) Sca-1+ stem cell survival and engraftment in the infarcted heart: dual role for preconditioning-induced connexin-43. Circulation 119: 2587-2596.

93. Kofidis T, Lebl DR, Martinez EC, Hoyt G, Tanaka M, et al. (2005) Novel injectable bioartificial tissue facilitates targeted, less invasive, large-scale tissue restoration on the beating heart after myocardial injury. Circulation 112 (9 Suppl): I173-I177.

94. Davis ME, Hsieh PC, Takahashi T, Song Q, Zhang S, et al. (2006) Local myocardial insulin-like growth factor 1 (IGF-1) delivery with biotinylated peptide nanofibers improves cell therapy for myocardial infarction. Proc Natl Acad Sci U S A 103: 8155-8160.

95. Ruvinov E, Leor J, Cohen S (2011) The promotion of myocardial repair by the sequential delivery of IGF-1 and HGF from an injectable alginate biomaterial in a model of acute myocardial infarction. Biomaterials 32: 565-578.

96. Cittadini A, Monti MG, Petrillo V, Esposito G, Imparato G,et al. (2011) Complementary therapeutic effects of dual delivery of insulin-like growth factor-1 and vascular endothelial growth factor by gelatin microspheres in experimental heart failure. Eur J Heart Fail 13: 1264-1274.

97. Wang Y, Liu XC, Zhao J, Kong XR, Shi RF, et al. (2009) Degradable PLGA scaffolds with basic fibroblast growth factor: experimental studies in myocardial revascularization. Tex Heart Inst J 36: 89-97.

98. Yang Y, Gruwel ML, Dreessen de Gervai P, Sun J, Jilkina O, et al. (2012) MRI study of cryoinjury infarction in pig hearts: i. Effects of intrapericardial delivery of bFGF/VEGF embedded in alginate beads. NMR Biomed 25: 177-188.

99. Webber MJ, Han X, Murthy SN, Rajangam K, Stupp SI, et al. (2010) Capturing the stem cell paracrine effect using heparin-presenting nanofibres to treat cardiovascular diseases. J Tissue Eng Regen Med 4: 600-610.

100. Garbern JC, Minami E, Stayton PS, Murry CE (2011) Delivery of basic fibroblast growth factor with a $\mathrm{pH}$-responsive, injectable hydrogel to improve angiogenesis in infarcted myocardium. Biomaterials 32: 2407-2416. 